\title{
In Vitro studies on changes in selected biochemical parameters and morphology of Sertoli cells in mice overexpressing bovine growth hormone
}

\author{
M. Bhaskar \\ Department of Zoology, S.V. University, Tirupati - 517 501, A.P. India
}

\begin{abstract}
The aim of the present study was to investigate the changes in selected biochemical variables in Sertoli cells isolated from testis of mice (PEPCK-bGH) overexpressing growth hormone. Significant increase in the levels of total proteins (108.33\%; $p<0.001)$, lactic acid (95.23\%; $p<0.001)$, DNA (155.42\%; $p<0.001)$ and RNA (90.00\%; $p<0.001)$ were observed in transgenic Sertoli cells as compared to normal Sertoli cells. Further, cultured transgenic Sertoli cells exhibited distinct nucleus over a period of 5 days and on day 7, exhibited accelerated proliferation as compared to normal Sertoli cells. From the results, it can be concluded that growth hormone at least in part mediates modulation of selected biochemical variables to influence Sertoli cell morphology thereby spermatogenesis in mice.
\end{abstract}

Keywords - DNA, lactic acid, PEPCK-bGH transgenic mice, RNA, Sertoli cells, total proteins

\section{Introduction}

Spermatogenesis is one of the testicular functions that are topographically and functionally coordinated by Sertoli cells. It is well established that, many factors including hormones and their crosstalk in a precise manner appears to be important in the regulation of sperm production. Among a range of hormones, growth hormone $(\mathrm{GH})$ plays an important role in the regulation of repertoire of pathways including spermatogenesis (1). Many andrological studies claimed that GH exerts its effects either directly and/or indirectly in the regulation of spermatogenesis. Firstly, direct effects are believed to be through GH receptors localized on hypothalamus and gonads (2), thereby Sertoli cell functions and secondly, indirect effects contribute to the GH coordination of hormones of hypothalamo-pituitary-testicular axis such as follicle stimulating hormone (FSH), leutinizing hormone ( $\mathrm{LH}$ ) and testosterone to influence testicular functions (3). Thus, it seems apparent that GH at least in part targets spermatogenesis. However, it is of major concern to understand the mechanism(s) of action of GH on spermatogenesis, since during recent past; manipulation of GH is widely used in animal husbandry and in medicine (4, 5, 6, 7 and 8). Transgenic mice (PEPCK-bGH) overexpressing bovine growth hormone are one of the well known animal models to understand the physiological effects of GH. Earlier, it has been suggested that transgenic mice over expressing bGH under rat PEPCK were good experimental models to study reproductive functions including spermatogenesis (9). Therefore, for the present study, mice overexpressing bGH were used to determine the changes in total proteins, lactic acid, DNA, and RNA of Sertoli cells. Further, studies were also emphasized on the effect of GH on Sertoli cell morphology.

\subsection{Animals}

\section{Materials and Methods}

Transgenic animals used in the present study were derived from a single male founder produced by micro-injection of the phosphoenol pyruvate carboxykinase (PEPCK) promoter region (300-bp) bGH, hybrid gene into the male pro-nucleus of single cell embryos. This breeding system results in a production of approximately equal number of hemizygous transgenic and normal (Non-Transgenic) offspring, refer to as controls. The animals were fed ad libitum a standard laboratory rodent diet (Teklad 6\% rat/mouse diet, 002'; Herlan Sprague Dawley, Madison W.I; 24\% protein, 6\% fat) and tap water. Litters were weaned between 20 and 22 days of age (day of birth $=$ day ' 0 '), and male litters are taken for the present study. The identification and selection of these animals were based on earlier reports (10). 


\subsection{Experimental Design}

The animals were divided into two groups. Mice in group 1 served as controls and mice in group 2 treated as experimental or transgenic (Tr). Each group consists of 8 mice.

\subsection{Sertoli Cell Culture Studies}

Prior to the isolation and culture studies, testis were immediately removed and weighed to its nearest milligram. After, weighing, the isolation and culture of Sertoli cells from testis of transgenic and non-transgenic mice was based on Welsh and Wiebe (11). The final concentration of cells was adjusted to 2000 clusters $/ 2 \mathrm{ml}$ using a hematocytometer. An area of $1 \mathrm{~cm}^{2}$ surrounding the centre of each dish was marked on the outer surface of the bottom, under a sterile hood. Approximately 200 clusters per $2 \mathrm{ml}$ of incubation media were plated in 35 $\mathrm{mm}$ pre-marked dishes. All incubations were done in culture media containing antibiotic and antimycotic compounds (200 U penicillin/ml, $200 \mathrm{ng}$ streptomycin/ml, $0.5 \mathrm{ng}$ amphotericin $\mathrm{B} / \mathrm{ml}$ and $100 \mu \mathrm{g}$ gentamycin/ml). After plating, all dishes were incubated at $34 \pm 1^{\circ} \mathrm{C}$ in an atmosphere of $5 \% \mathrm{CO}_{2}+95 \%$ air. The day of plating was considered as day 0 of culture. The dishes were not disturbed until day 2 of culture.

\subsection{Evaluation Of Culture Capabilities:}

2.4.1. Attachment

On second day of culture (42 hours after plating) the dishes were shaken gently and media was collected to count the number of unattached clusters in each dish. The attached cells were fed with fresh media.

\subsubsection{Spreading:}

The number of attached clusters in the premarked areas $\left(1 \mathrm{~cm}^{2}\right)$ was determined under microscope (200 $\mathrm{X}$ magnification) and the percent of attached clusters showing spreading of the attached cells was recorded, 48 hours after plating. This was referred to as percent spreading.

\subsubsection{Maintenance capacity:}

All dishes were replaced with fresh media of desired combinations every 24 hours and day $4^{\text {th }}$ of culture the premarked area was observed again to count the number of attached Sertoli cell clusters.

\subsubsection{Culture Characteristics:}

Cultured cells were treated with $20 \mathrm{mM}$ Tris buffer (pH 7.2) for 7 minutes on day 3 of culture to remove germ cells. Media was replaced every 24 hours and culture characteristics were determined on day 4 of culture. Cells from 20 microscopic fields (X 100) in each plate were observed under phase contrast microscope after staining for viability and histochemical identification of specific cell types.

\subsubsection{Morphological Observation Of Sertoli Cells}

For the light microscopic observations of Sertoli cells, cells in culture were fixed in buffered formalin and stained with Gaemsam (Stock solution by harteco, Gebbston, NJ, diluted 50-fold with methanol) for 30 minutes at room temperature. Excess stain was washed and stained cells were kept overnight in distilled water which help to visualize the shape of Sertoli cells.

\subsection{Assays}

Total proteins, lactic acid, DNA and RNA from normal and transgenic Sertoli Cells were determined by methods described previously $(12,13$, and 14$)$.

\subsection{Statistical Analysis}

Differences between groups were analyzed for statistical significance by using student's t-test on raw data. $p<0.01$ was considered as significant.

\subsection{Toxicity}

\section{Results} experiments.

No clinical signs of toxicity were observed in any of the control and transgenic mice used in the

\subsection{Changes In Body And Testicular Weights Of Transgenic And Normal Mice}

The mean body weight of bGH transgenic mice was significantly higher $(87.56 \%)$ than the average body weight of normal siblings (Table 1$)$. The mean testes weight $(68.09 \%)$ was also significantly $(\mathrm{p}<0.001)$ higher in transgenic mice as compared to testis of normal siblings. 


\subsection{Changes In Morphology Of Sertoli Cells Of Transgenic And Normal Mice}

The results of viability studies revealed absence of contamination with Leydig and peritubular cells on day 7 of culture of normal and transgenic Sertoli cells (Table 2). Examination of cultured Sertoli cells isolated from testes of transgenic mice showed a confluent monolayer in transgenic Sertoli cells by day 5 of culture while Sertoli cells cultured from testes of normal siblings were unable to do so (Fig. 1A). Sertoli cells of normal mice showed distinct nucleus on day 7 of culture. On the other hand, Sertoli cells isolated from testes of transgenic mice exhibited distinct nucleus on day 5 (Fig. 1B) and on day 7 showed active division (Fig. 1D) as compared to Sertoli cells isolated from testes of normal mice (Fig. 1C).

\subsection{Changes in selected biochemical variables in Sertoli cells of transgenic and normal mice}

Table 3 represents the changes in the levels of DNA, RNA, total proteins and lactic acid of Sertoli cells isolated from testes of transgenic and normal mice. In the present study, significant $(p<0.001)$ increase in the levels of total proteins, lactic acid, DNA and RNA were observed in transgenic Sertoli cells as compared to normal Sertoli cells. The percent increase in total proteins, lactic acid, DNA and RNA in transgenic Sertoli cells as compared to normal Sertoli cells were 108.33, 95.23, 155.42 and 90.00, respectively (Table 3).

\section{Discussion}

The purpose of the present study was twofold: 1) to know the effect of GH on selected biochemical parameters in Sertoil cells and 2) to understand the effect of GH-induced changes in morphology of Sertoli cells. The results of present study indicated that, a significant increase in the body and testicular weights of mice overexpressing bGH was observed as compared to normal mice. The results are in consonance with earlier reports (10). The observed increase in the body and testis weights might be due to ectopic expression of GH under the transcriptional regulation of PEPCK promoter (15). The findings of the present study also suggests that total proteins, DNA, RNA and lactate levels were significantly increased in transgenic Sertoli cells as compared to the normal Sertoli cells during culture studies over a period of 5 days.

Earlier it has been demonstrated that mice overexpressing growth hormone under the regulation of PEPCK promoter exhibited variations in the biochemical variables in the testis of mice (10). It is well known that nucleic acids are vital macromolecules of the cells. DNA is believed to be a carrier of biological information and RNA is an important nucleic acid for protein synthesis. Thus, increased levels of DNA, RNA and total proteins in transgenic Sertoli cells indicate the direct modulatory effects of GH on regulatory enzymes of DNA machinery, transcription and translation. Earlier experiments conducted by Carter et al. (16) demonstrated that growth hormone modulates events precede DNA synthesis, during DNA synthesis and also mitotic division in rats. Further, in vitro studies also suggested that growth hormone has ability to influence protein synthesis (17) and also RNA polymerase activity (18). In the present study, a significant increase in the lactate levels was observed in the cultured transgenic Sertoli cells over normal Sertoli cells. The increased levels of lactate in mice overexpressing bGH indicate increased metabolism of glucose by Sertoli cells via cytosolic glycolysis. The role of lactate in the regulation of spermatogenesis is well acknowledged. Generally it is well accepted that lactate appears to act as transcription survival factor and also act as substrate for germ cells in the production of ATP through mitochondrial oxidative phosphorylation (19).

One of the important findings of the present study suggests that Sertoli cells isolated from transgenic mice exhibited active proliferation than the Sertoli cells isolated from normal mice. The proliferation of transgenic Sertoli cells reflects greater availability of synthetic machinery such as DNA, RNA and total proteins. The results also suggest that recruitment of initiation of proliferation in transgenic Sertoli cells were faster than that of normal Sertoli cells. This aspect is very important at the perspective of spermatogenesis; since active proliferation increases Sertoli cell population thereby sustains sperm production. In mammals, Sertoli cells of testis play a key role in the regulation of initiation and maintenance of spermatogenesis. Moreover, the proliferative activity of Sertoli cells determines the maximum spermatogenic potential later in life (20). The increased proliferative effects of transgenic Sertoli cells indicate GH-induced mitogenic effects on cultured cells. Previously, it has been suggested that since Sertoli cells have ability to support only a limited number of germ cells thereby sperm production, the early proliferative activity of Sertoli cells at immature stages in mammals is of paramount importance (21). In consistent with the results obtained in the present study, earlier it has been reported that transgenic mice overexpressing bGH under the transcriptional control of PEPCK showed greater number of daily sperm density per gram testis in mice over normal siblings (10).From the results, it can be concluded that GH promotes protein, lactate and nucleic acid levels of transgenic Sertoli cells in vitro. Moreover, GH induced proliferative effects of Sertoli cells might provide valuable information regarding hormonal control of spermatogenesis thereby male fertility. 


\section{Conclusion}

In view of great interest in the use of GH and transgenic technology in animal industry and in medicine, it is of prime importance to know the impact of GH on gonadal functions. Transgenic mice used in the present study posses overexpressing GH and therefore the results provide new information on the effects of prolonged exposure to elevated GH levels in vivo on the function of Sertoli cells under in vitro. However, further studies with spermatogenic regulatory hormones such as follicle stimulating hormone and testosterone on transgenic Sertoli cells is required since both these hormones regulate spermatogenesis at different stages of mammalian development.

\section{Acknowledgements}

This study was supported by Rockefeller Foundation, New York, USA (Ref: 93022). The author is thankful to Dr. J.N. Rao, Dr. V. Chandrasekhar and Dr. Michael Collard for sharing their experience in culture of Sertoli cells and completing the work. The author also acknowledges Dr. Andrej Bartke, for his mentoring and providing laboratory facilities in Department of Physiology, School of Medicine, Southern Illinois University, Carbondale, IL-62901, USA.

\section{REFERENCES}

[1]. N. Magon, S. Singh, A. Saxena and R. Sahay, Growth hormone in male infertility, Indian Journal of Endocrinology and Metabolism 15, 2011, 248-249.

[2]. A. Bartke, V. Chandrashekar and R.W. Steger, Effects of growth hormone on neuroendocrine function, Acta Neurobiologiae Experimentalis 56, 1996, 833-842.

[3]. D. Madhukar and S. Rajender, Hormonal treatment of male infertility: Promises and pitfalls, Journal of Andrology 30, 2009, 95112 .

[4]. Z. Shoham, G.S. Conway, H. Ostergaard, N. Lahlou, P. Bouchard and H.S. Jacobs, Cotreatment with growth hormone for induction of spermatogenesis in patients with hypogonadotropic hypogonadism, Fertility and Sterility 57, 1992, 1044-1051.

[5]. C. Carani, A.R. Granata, M. De Rosa, C. Garau, S. Zarrilli, L. Paesano, A. Colao, P. Marrama and G. Lombardi, The effect of chronic treatment with GH on gonadal function in men with isolated GH deficiency, European Journal of Endocrinology 140, 1999, 224-230.

[6]. J.M.S. Barlett, H.M. Charlton, I.C.A.F. Robison and E. Nieschlag, Pubertal development and testicular function in the GH-deficient rat. Journal of Endocrinology 126, 1990, 193-201.

[7]. S. Kalra, B. Kalra and A. Sharma, Growth hormone improves semen volume, sperm count and motility in men with idiopathic normogonadotropic infertility, Endocrinology Abstracts 16, 2008, 613.

[8]. Z.J. Champion, M.H. Vickers, C.G. Gravance, B.H. Breier and P.J. Casey, Growth hormone or insulin-like growth factor-I extends longevity of equine spermatozoa in vitro, Theriogenology 57, 2002, 1793-1800.

[9]. M.G. Castro, Transgenic models in endocrinology, (USA: Kluwer Academic Publishers, 2001).

[10]. A. Bartke, E.M. Naar, L. Johnson, M.R. May, M. Cecim, J.S. Yun and T.E. Wagner, Effects of expression of human or bovine growth hormone genes on sperm production and male reproductive performance in four lines of transgenic mice, Journal of Reproduction and Fertility 95, 1992, 109-118.

[11]. M.J. Welsh and J.P. Wiebe, Rat Sertoli cells: A rapid method for obtaining viable cells, Endocrinology 96, 1975, 618-624.

[12]. K.W. Giles and A. Myers, An Improved Diphenylamine Method for the Estimation of Deoxyribonucleic Acid, Nature 206, 1965, 93.

[13]. M. Bradford, A Rapid and Sensitive Method for the Quantitation of Microgram Quantities of Protein Utilizing the Principle of Protein-Dye Binding, Analytical Biochemistry 72, 1976, 248-254.

[14]. H.J. Hohorst, L(+)-Lactate: Determination with lactic dehydrogenase and DPN. In H.U. Bergmeyer (Ed.), Methods of Enzymatic Analysis, (Weinheim: Verlag Chemie, 1965) 266-270.

[15]. M. Cecim, Growth allometry of skin, carcass and organs in mice transgenic for bovine growth hormone, In Program of the 72nd Annual Meeting of the Endocrine Society, Abstract 910, (Baltimore, USA: Williams and Wilkins, 1990).

[16]. D.B. Cater, B.E. Holmes and L.K. Mee, The effect of growth hormone upon cell divison and nucleic acid synthesis in the regeneration of liver of rat, Biochemistry Journal 66, 1957, 482-486.

[17]. L.S. Jefferson and A. Korner, A direct effect of growth hormone on the incorporation of precursors into proteins and nucleic acids of perfused rat liver, Biochemistry Journal 104, 1967, 826-832.

[18]. A.E. Pegg and A. Sc. Korner, Growth hormone action on rat liver RNA polymerase, Nature 205, 1965, 904.

[19]. M.F. Reira, S.B. Meroni, G.E. Gomez, H.F. Schteingart, E.H. Pellizzari and S.B. Cigorraga, Regulation of lactate production by FSH, IL1 beta and TNF alpha in rat Sertoli cells, General and Comparative Endocrinology 122, 2001, 88-97.

[20]. F.R.M.B. Silva, L.D. Leite and G.F. Wassermann, Rapid signal transduction in Sertoli cells. European Journal of Endocrinology $147,2002,425-433$.

[21]. W.H. Walker, Molecular mechanisms controlling sertoli cell proliferation and differentiation, Endocrinology 144, 2003, 3719-3721. 
Table 1: $\quad$ Changes in whole body weight and testis weight of normal and transgenic mice

\begin{tabular}{|l|l|l|}
\hline Parameter & Normal & Transgenic \\
\hline Body weight $(\mathrm{g})$ & $8.12 \pm 0.64$ & $15.23 \pm 0.94$ \\
& & $(87.56)$ \\
& & $\mathrm{p}<0.001$ \\
\hline Testis weight $(\mathrm{mg})$ & $35.82 \pm 2.03$ & $60.12 \pm 5.64$ \\
& & $(68.09)$ \\
& & $\mathrm{p}<0.001$ \\
\hline
\end{tabular}

Values are mean \pm S.D. of 8 individual mice.

Values in the parentheses are percent change from normal mice.

Table 2: Viability of Sertoli cells and contamination with Leydig and peritubular cells on day 7 of culture of normal and transgenic Sertoli cells

\begin{tabular}{|c|c|c|}
\hline Parameter & Normal & Transgenic \\
\hline Viable cells (\%) & $89.31 \pm 4.05$ & $\begin{array}{l}97.42 \pm 1.86 \\
(9.082) \\
p<0.001\end{array}$ \\
\hline Leydig cells (\%) & 0.00 & 0.00 \\
\hline Peritubular cells $(\%)$ & $2.21 \pm 0.12$ & $\begin{array}{l}1.34 \pm 0.038 \\
(-39.37) \\
p<0.001\end{array}$ \\
\hline
\end{tabular}

Values are mean \pm S.D.

Values in the parentheses are percent change from normal Sertoli cells.

Table 3: Changes in the levels of total proteins, DNA, RNA and lactate of normal and transgenic Sertoli cells.

\begin{tabular}{|c|c|c|}
\hline Parameter & Normal & Transgenic \\
\hline $\begin{array}{l}\text { Total proteins } \\
\left(\mu \mathrm{g} / 10^{-3} \mathrm{~g} \text { cell mass }\right)\end{array}$ & $60.14 \pm 3.42$ & $\begin{array}{l}125.16 \pm 8.31 \\
(108.33) \\
p<0.001\end{array}$ \\
\hline $\begin{array}{l}\text { DNA } \\
\left(\mu \mathrm{g} / 10^{-3} \mathrm{~g} \text { cell mass }\right)\end{array}$ & $0.83 \pm 0.031$ & $\begin{array}{l}2.1 \pm 0.16 \\
(155.42) \\
p<0.001 \\
\end{array}$ \\
\hline $\begin{array}{l}\text { RNA } \\
\left(\mu \mathrm{g} / 10^{-3} \mathrm{~g} \text { cell mass }\right)\end{array}$ & $20.13 \pm 1.42$ & $\begin{array}{l}38.13 \pm 1.91 \\
(90.00) \\
p<0.001\end{array}$ \\
\hline $\begin{array}{l}\text { Lactic acid } \\
\left(\mu \mathrm{g} / 10^{-3} \mathrm{~g} \text { cell mass }\right)\end{array}$ & $0.021 \pm 0.0012$ & $\begin{array}{l}0.041 \pm 0.0031 \\
(95.23) \\
p<0.001\end{array}$ \\
\hline
\end{tabular}

Values are mean \pm S.D.

Values in the parentheses are percent change from normal Sertoli cells. 
Figure 1: Morphological changes of Sertoli cells of normal and transgenic mice
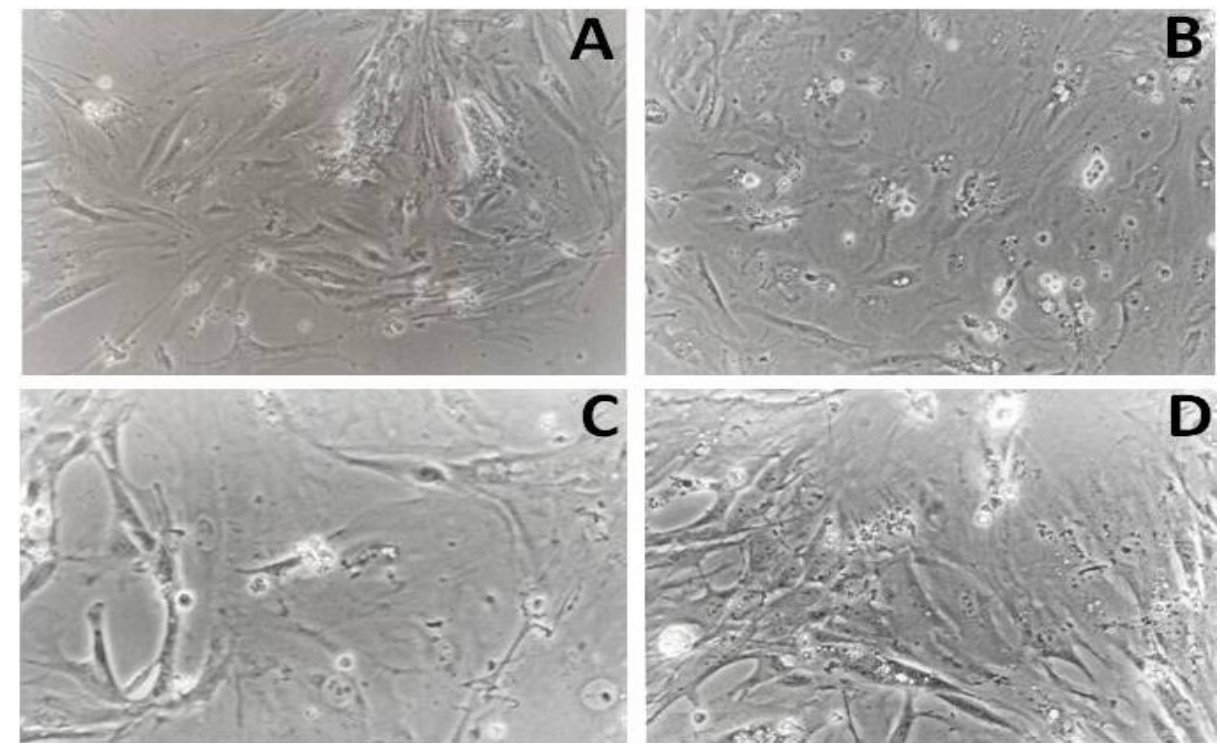

$\begin{array}{ll}\text { A: } & 5^{\text {th }} \text { day culture of normal Sertoli cells exhibits no distinct nucleus } \\ \text { B: } & 5^{\text {th }} \text { day culture of transgenic Sertoli cells exhibits distinct nucleus } \\ \text { C: } & 7^{\text {th }} \text { day culture of normal Sertoli cells grow in size and exhibits distinct nucleus } \\ \text { D: } & 7^{\text {th }} \text { day culture of transgenic Sertoli cells exhibits active division and differentiation }\end{array}$ 